\title{
COMPACTAÇÃO DO SOLO E MANEJO DA ÁGUA. I: EFEITOS SOBRE A ABSORÇÃO DE N, P, K, MASSA SECA DE RAÍZES E PARTE AÉREA DE PLANTAS DE ARROZ
}

\author{
Soil compaction and water management. I: effects upon uptake of N, P, K, root \\ and shoot dry matter of rice plants
}

\author{
Roberto Dantas de Medeiros ${ }^{1}$, Antônio Alves Soares², Renato Mendes Guimarães²
}

\begin{abstract}
RESUMO
Com o presente trabalho objetivou-se avaliar os efeitos de seis níveis de compactação, associados a diferentes manejos de água, sobre a absorção de nitrogênio $(\mathrm{N})$, fósforo $(\mathrm{P})$ e potássio $(\mathrm{K})$, o desenvolvimento do sistema radicular e parte aérea de plantas de arroz. O experimento foi conduzido no período de setembro de 2002 a janeiro de 2003 em casa- de-vegetação da UFLA, em LavrasMG. Testou-se seis níveis de compactação do solo: $0 \%, 16 \%, 32 \%, 48 \%, 64 \%$ e $80 \%$ da amplitude de variação da densidade do solo $\left(0,25 \mathrm{~kg} \mathrm{dm}^{-3}\right)$, combinado com três teores de água no solo: solo saturado, irrigado quando eram consumidos de $25 \%$ a $30 \%$ e de $50 \%$ a $60 \%$ da água disponível, respectivamente. O manejo com maior disponibilidade de água no solo favoreceu as médias dos teores de $\mathrm{P}$ e de $\mathrm{K}$ na parte aérea das plantas, a produção de massa seca da raiz, o número de perfilhos por vaso e a massa seca da parte aérea das plantas de arroz, independentemente dos níveis de compactação do solo. Por outro lado, a compactação do solo diminuiu as médias de todas características avaliadas, independentemente do manejo de água. Entretanto, o manejo de água teve efeito mais limitante sobre a absorção dos nutrientes e a produção de massa seca da parte aérea das plantas do que a compactação do solo.
\end{abstract}

Termos para indexação: Oryza sativa, densidade do solo, umidade.

\begin{abstract}
The present work had as objective to evaluate the effects six compaction levels, associated with different water managements upon uptake of nitrogen $(\mathrm{N})$, phosphorus $(\mathrm{P})$ and potassium $(\mathrm{K})$, the development of root and shoot of rice plants. The experiment was conducted during the period of September 2002 to January 2003 in a greenhouse at UFLA university, in Lavras- MG. Six compaction levels were tested: $0 \%, 16 \%, 32 \%, 48 \%, 64 \%$ and $80 \%$ in a range of variation of soil density $\left(0.25 \mathrm{~kg} \mathrm{dm}^{-3}\right)$, combined with three soil water contents: saturated soil, irrigated when were consumed from $25 \%$ to $30 \%$ and from $50 \%$ to $60 \%$ of available water, respectively. The management with the greatest soil water availability favored the average of $\mathrm{P}$ and $\mathrm{K}$ contents in the shoot of the plants, root dry matter yield, number of tillers per pot and dry matter of the shoot of rice plant, regardless of soil compaction levels. On the other hand, soil compaction decreased the averages of all the characteristics evaluated, regardless water management. Nevertheless, water management had the most limiting effect on the uptake of nutrients and shoot dry matter of the plants than soil compaction.
\end{abstract}

Index terms: Oryza sativa, soil density, moisture.

(Recebido para publicação em 7 de junho de 2004 e aprovado em 12 de julho de 2005)

\section{INTRODUÇÃO}

$\mathrm{O}$ arroz é considerado, entre as principais espécies cultivadas, uma das mais sensíveis à compactação do solo, a qual se atribui como a principal causa do insucesso do cultivo do arroz de terras altas no sistema de plantio direto. Pois, considera-se que a macroporosidade do solo seja um fator imprescindível para o desenvolvimento do sistema radicular e da parte aérea das plantas de arroz, em quaisquer que sejam as condições climáticas (KLUTHCOUSKI, 1998; SÉGUY et al., 1999). Contudo, para o arroz irrigado por inundação, esse sistema vem sendo utilizado sem restrições, obtendo-se produtividades de grãos iguais (WEBER et al., 1999) e, ou, superiores (DIAS et al., 1995) às obtidas com a cultura cultivada no sistema de preparo do solo convencional. Logo, o teor de água no solo tem sido um fator fundamental para o desempenho da cultura do arroz no sistema de plantio direto.

Pesquisas mostram que a compactação do solo reduz o volume de macroporos enquanto os microporos permanecem praticamente inalterados (STONE et al., 2002). Assim, o desenvolvimento das raízes é afetado negativamente pela redução dos macroporos (SÉGUY et al., 1999), pelo aumento da resistência à penetração das raízes (STONE et al., 2002), pela diminuição da concentração de oxigênio, pela menor taxa de mineralização da matéria orgânica no solo, e difusão lenta de nutrientes e de oxigênio

\footnotetext{
${ }_{1}$ Pesquisador da Embrapa Roraima, D.Sc. em Fitotecnia - BR 174, Km 8 - Distrito Industrial Cx. P. 133 - $69301-970$ - Boa Vista, RO roberto@cpafrr.embrapa.br

2 Engenheiro Agrônomo, D.Sc. Fitotecnia, Professor do Departamento de Agricultura/UFLA - Cx. P. 3037 - $37200-000$ - Lavras, MG.
} 
para as raízes (COSTA, 1998; RIBEIRO, 1999), diminuindo então a disponibilidade e a absorção de água e de nutrientes (PEDROTTI et al., 1994). Além disso, a compactação aumenta a interação do íon de fosfato e de potássio com a superfície dos colóides, ao longo de sua trajetória de difusão, fazendo com que estes elementos tenham que se difundir cada vez mais próximo da superfície que os adsorvem (NOVAIS \& SMYTH, 1999).

Estudando o comportamento da beterraba em solo sob diferentes níveis de compactação e teores de água no solo, Hoffmann \& Jungk (1995) concluíram que o principal fator de restrição ao desenvolvimento do sistema radicular em solo compactado foi a resistência à penetração e não a aeração. Segundo Passioura (1991), o alongamento radicular só é possível quando a pressão de crescimento das raízes for maior do que a resistência mecânica do solo à penetração. Na predominância de microporosidade as raízes do arroz não conseguem reduzir seu diâmetro para penetrar nos microporos, menores que suas extremidades. Todavia, a resistência à penetração diminui com o aumento da umidade no solo. Assim, Hoffmann \& Jungk (1995) observaram que com a variação do potencial da água no solo de $-30 \mathrm{kPa}$ para - $10 \mathrm{kPa}$, a resistência do solo à penetração diminuiu em torno de $50 \%$.

Porém, a influência da compactação do solo sobre a absorção de nutrientes, o desenvolvimento do sistema radicular e da parte aérea das plantas depende da espécie, da classe de solo e do teor de água no solo. Leite et al. (2003) constataram que a compactação de até $3,0 \mathrm{~kg} \mathrm{dm}^{-3}$ em um Latossolo de textura média aumentou a massa da matéria seca da parte aérea das plantas de arroz (MSPA). Silveira (2002) também obteve aumento de $48 \%$ na MSPA de plantas de arroz no solo sob a densidade de $1,39 \mathrm{~kg} \mathrm{dm}^{-3}$ em relação à produção obtida no solo sob a densidade de $1,12 \mathrm{~kg} \mathrm{dm}^{-3}$. Por sua vez, Rosolem et al. (1994) observaram que a compactação do solo reduziu o crescimento radicular do milho, mas não afetou a produção de matéria seca total nem da parte aérea das plantas.

Quanto ao manejo de água, o arroz requer alto teor de umidade no solo para o seu desenvolvimento normal. Ocorrendo déficit hídrico no solo, próximo às raízes, os estômatos se fecham, ajustando a resistência estomatal para reduzir o fluxo de vapor e diminui a transpiração. Nestas condições, as taxas fotossintética e respiratória são afetadas e, conseqüentemente, reduzem a produção de matéria seca total e a produtividade de grãos (LIER, 2000).

Por outro lado, a alta disponibilidade de água no solo diminui a resistência à penetração das raízes
(HOFFMAN \& JUNGHK, 1995), favorece a taxa fotossintética nas folhas, a produção de carboidratos e a absorção de nutrientes pelas plantas (CARVALHO JUNIOR, 1987; CRUSCIOL, 2001). Isso ocorre devido ao aumento dos fluxos de massa e difusão dos nutrientes no solo (COSTA, 1998; RIBEIRO, 1999); a redução e a solubilização dos óxidos de ferro, incrementando a produção de massa seca da raiz e da parte aérea das plantas (CARVALHO JUNIOR, 1987; CRUSCIOL, 2001; PEDROTTI et al., 1994). Porém, este efeito não depende da presença da lâmina de água sobre a superfície do solo, basta que o mesmo esteja saturado (GOMES et al., 1985).

Para tanto, implantou-se este trabalho com o objetivo de avaliar a cultura do arroz sob seis níveis de compactação do solo associado a diferentes manejos de água no solo e comparar seus efeitos sobre os teores de $\mathrm{N}$, $\mathrm{P}$ e K na parte aérea de plantas de arroz, a produção de massa seca de raízes e da parte aérea de plantas, bem como sobre o número de perfilhos.

\section{MATERIAL E MÉTODOS}

O experimento foi conduzido em casa-de-vegetação do Departamento de Agricultura da Universidade Federal de Lavras - UFLA, em Lavras-MG, no período de setembro de 2002 a janeiro de 2003. Utilizou-se a cultivar de arroz de terras altas BRS Liderança e um solo de várzea classificado como Neossolo Flúvico, coletado na profundidade de 0 a $20 \mathrm{~cm}$, que analisado apresentou as seguintes características químicas e físicas: $\mathrm{pH}\left(\mathrm{H}_{2} 0\right)=5,7 ; \mathrm{Ca}^{2+}=4,9$ $\mathrm{cmol}_{\mathrm{c}} \mathrm{dm}^{-3} ; \mathrm{Mg}^{2+}=1,6 \mathrm{cmol}_{\mathrm{c}} \mathrm{dm}^{-3} ; \mathrm{Al}^{3+}=0,1 \mathrm{cmol}_{\mathrm{c}} \mathrm{dm}^{-3} ; \mathrm{P}=$ $19,4 \mathrm{mg} \mathrm{dm}^{-3} ; \mathrm{k}=225,0 \mathrm{mg} \mathrm{dm}^{-3} ; \mathrm{MO}=20 \mathrm{~g} \mathrm{~kg}^{-1} ;$ areia $=80$ $\mathrm{g} \mathrm{kg}^{-1} ;$ silte $=350 \mathrm{~g} \mathrm{~kg}^{-1} ;$ argila $=570 \mathrm{~g} \mathrm{~kg}^{-1}$ (classe textural argila), determinadas segundo metodologia apresentada em Embrapa (1997).

Utilizou-se o delineamento inteiramente ao acaso em esquema fatorial $6 \times 3$, sendo seis níveis de compactação do solo: $0 \%, 16 \%, 32 \%, 48 \%, 64 \%$ e $80 \%$ da amplitude de variação da densidade do solo ( $\Delta \mathrm{ds})$, equivalendo às densidades de solo $1,11 \mathrm{~kg} \mathrm{dm}^{-3} ; 1,15 \mathrm{~kg} \mathrm{dm}^{-3} ; 1,19 \mathrm{~kg} \mathrm{dm}^{-3}$; $1,23 \mathrm{~kg} \mathrm{dm}^{-3} ; 1,27 \mathrm{~kg} \mathrm{dm}^{-3}$ e 1,31 kg dm${ }^{-3}$, combinados com três manejos de água no solo: M1 - solo saturado, isto é, $100 \%$ dos poros ocupado com água, M2 - irrigação quando eram consumidos de 25 a $30 \%$ da água disponível (AD) para as plantas e M3 - irrigação quando eram consumidos de 50 a $60 \%$ da água disponível. Considerou-se $\mathrm{AD}$, o teor de água retida no solo na tensão $0,006 \mathrm{MPa}$ menos o teor de água retida no solo na tensão de 1,5 MPa.

A compactação máxima do solo foi determinada pelo teste de Procton normal, alcançando-se a densidade máxima 
de $1,36 \mathrm{~kg} \mathrm{dm}^{-3}$ com $26 \%$ de umidade. Determinou-se a amplitude de variação da densidade do solo ( $\Delta \mathrm{ds})$ através da expressão: $\Delta \mathrm{ds}=$ densidade máxima $\left(1,36 \mathrm{~kg} \mathrm{dm}^{-3}\right)$ - a densidade do solo solto peneirado $\left(1,11 \mathrm{~kg} \mathrm{dm}^{-3}\right)=0,25 \mathrm{~kg} \mathrm{dm}^{-3}$.

Cálculo das densidades do solo:

Nível 0: $0 \%$ da $\Delta \mathrm{ds}=$ a densidade mínima do solo sem compactação $=1,11 \mathrm{~kg} \mathrm{dm}^{-3}$.

Nível 1: $16 \%$ da $\Delta$ ds e as demais densidades foram determinadas por regra de três simples:

$0,25-100 \backslash \mathrm{x}=(0,25 \mathrm{x} 16) / 100=0,04 \backslash \Delta \mathrm{ds}$ a $16 \%=1,11+$ $\mathrm{x}-16, \quad 0,04=1,15 \mathrm{~kg} \mathrm{dm}^{-3}$.

Nível 2: $32 \%$ da $\Delta$ ds: $\mathrm{x}=(0,25 \mathrm{x} 32) / 100=0,08 \Rightarrow 1,11+0,08=$ $1,19 \mathrm{~kg} \mathrm{dm}^{-3}$.

Nível 3: $48 \%$ da $\Delta$ ds: $\mathrm{x}=(0,25 \times 48) / 100=0,12 \Rightarrow 1,11+0,12=$ $1,23 \mathrm{~kg} \mathrm{dm}^{-3}$.

Nível 4: $64 \%$ da $\Delta$ ds: $x=(0,25 \times 64) / 100=0,16 \quad 1, \not+0,16$ $=1,27 \mathrm{~kg} \mathrm{dm}^{-3}$.

Nível 5: $80 \%$ da $\Delta$ ds: $\mathrm{x}=(0,25 \mathrm{x} 80) / 100=0,20 \quad 1, \$+0,20$ $=1,31 \mathrm{~kg} \mathrm{dm}^{-3}$.

As parcelas foram constituídas por vasos confeccionados em tubos de PVC, com $200 \mathrm{~mm}$ de diâmetro por $35 \mathrm{~cm}$ de altura, contendo uma coluna de solo de 7,018 $\mathrm{dm}^{-3}$ (24 cm de altura x $20 \mathrm{~cm}$ de diâmetro) deixando-se uma borda livre de $11 \mathrm{~cm}$. $\mathrm{O}$ solo foi seco à sombra e peneirado em malha de $4,76 \mathrm{~mm}$. A compactação do solo foi produzida artificialmente por meio de uma prensa hidráulica.

A adubação de plantio foi realizada antes da compactação do solo, colocando-se por vaso: $2,41 \mathrm{~g}$ de fosfato monobásico de potássio + 7,31 g de MAP + 2,15 g de sulfato de magnésio $+2,47 \mathrm{~g}$ de nitrato de cálcio e $0,50 \mathrm{~g}$ de FTE BR 13. Em cobertura, foram efetuadas três adubações: a primeira aos 25 dias após a emergência (d.a.e.), aplicando-se $0,97 \mathrm{~g}$ de nitrato de potássio $+1,74 \mathrm{~g}$ de nitrato de amônia por vaso; a segunda e a terceira foram efetuadas aos 50 e 70 d.a.e., respectivamente, aplicando-se 2,20 g de nitrato de amônia por vaso.

A semeadura foi realizada, utilizando-se oito sementes por vaso. Dez dias após a emergência das plântulas, efetuou-se o desbaste, deixando-se duas plantas por vaso. A partir daí, estabeleceu-se os tratamentos com manejo de água que foram monitorados por meio de pesagens, até o final do ciclo das plantas.

Foram avaliados os teores de N, P e K na parte aérea das plantas, a massa seca de raízes vaso ${ }^{-1}$, o número de perfilhos vaso-1 e a massa seca da parte aérea das plantas de arroz, determinados após a colheita de grãos.

Os teores de $\mathrm{N}, \mathrm{P}$ e $\mathrm{K}$ na parte aérea das plantas foram determinados segundo metodologia apresentada em Tedesco et al. (1995). A massa seca de raízes foi determinada, separando-as do solo por meio de lavagem com jato de torneira e peneiras com malha de $4 \mathrm{~mm}$, as quais foram para a estufa a 70 ÚC e pesadas, após atingir massa constante. A massa seca da parte aérea das plantas refere-se à massa de toda planta sem a ráquis, seca em estufa até atingir massa constante. $\mathrm{O}$ número de perfilhos foi determinado por meio da contagem de todos os colmos existentes em cada vaso, na véspera da colheita dos grãos.

\section{RESULTADOS E DISCUSSÃO}

Todas as características avaliadas foram submetidas à análise de variância $(\mathrm{P} \leq 0,05)$, cujos resultados são apresentados na Tabela 1 . As médias dos teores de N, P e $\mathrm{K}$ na parte aérea das plantas, da massa seca de raízes e da parte aérea das plantas e do número de perfilhos por vaso foram estatisticamente influenciados pela compactação do solo e pelo manejo de água, bem como pela interação compactação x manejos de água; exceto para a característica número de perfilhos por vaso, que não sofreu interferência da compactação combinada aos diferentes manejos de água.

TABELA 1 - Resumo dos resultados da análise de variância para as características avaliadas, envolvendo diferentes níveis de compactação (C), manejos de água (MA) e interações. UFLA, Lavras-MG, 2004.

\begin{tabular}{|c|c|c|c|c|c|}
\hline \multirow{2}{*}{ Características avaliadas } & \multirow{2}{*}{$\begin{array}{l}\text { Média } \\
\text { geral }\end{array}$} & \multirow{2}{*}{$\begin{array}{l}\text { CV } \\
(\%)\end{array}$} & \multicolumn{3}{|c|}{ Quadrado médio } \\
\hline & & & $\mathbf{C}$ & MA & C $\mathbf{X}$ MA \\
\hline Teores de $\mathrm{N}$ parte aérea $\left(\mathrm{mg}\right.$ vaso $\left.^{-1}\right)$ & 647,2 & 7,5 & $102516^{* *}$ & $30754 * *$ & $87 * *$ \\
\hline Teores de $\mathrm{P}$ parte aérea $\left(\mathrm{mg} \mathrm{vaso}^{-1}\right)$ & 45,6 & 8,7 & $304 * *$ & $2496 * *$ & $46 * *$ \\
\hline Teores de K parte aérea (mg vaso ${ }^{-1}$ ) & 1696 & 4,3 & $260035 * *$ & $1100321 * *$ & $12880 * *$ \\
\hline Massa seca de raiz $\left(\mathrm{g} \mathrm{vaso}^{-1}\right)$ & 17,4 & 6,2 & $13^{* *}$ & $7 * *$ & $3 * *$ \\
\hline Número de perfilhos vaso ${ }^{-1}$ & 23,1 & 5,4 & $52 * *$ & $90 * *$ & 1,1 \\
\hline Massa seca da parte aérea $\left(\mathrm{g} \mathrm{vaso}^{-1}\right)$ & 66,1 & 6,5 & $825 * *$ & $2051 * *$ & $37 * *$ \\
\hline
\end{tabular}

**, * F significativo, nos níveis de $1 \%$ e $5 \%$ de probabilidade, respectivamente.

Ciênc. agrotec., Lavras, v. 29, n. 5, p. 940-947, set./out., 2005 
Os resultados das médias dos teores de nitrogênio $(\mathrm{N})$, fósforo $(\mathrm{P})$ e potássio $(\mathrm{K})$ acumulados na parte aérea das plantas, obtidas em função do desdobramento da interação manejo de água x níveis de compactação são mostrados nas Figuras 1a, 1b e 1c. Verifica-se que os teores de $\mathrm{N}, \mathrm{P}$ e K foram reduzidos à medida que se aumentaram os níveis de compactação, independentemente do manejo de água, cujos valores se ajustaram a modelos de regressão linear e decrescente. Portanto, houve uma associação inversa entre os níveis de compactação e os teores de N, P e $\mathrm{K}$ acumulados na parte aérea das plantas.

Pela Figura 1a, verifica-se que a compactação reduziu os teores de $\mathrm{N}$, atingindo no manejo $\mathrm{M} 1$, o máximo de 24,9\%; nos manejos M2 e M3, essa redução chegou a $45,7 \%$ e $34,6 \%$, respectivamente, em relação aos teores máximos $\left(728,95 \mathrm{mg}_{\text {vaso }}{ }^{-1}, 897,5 \mathrm{mg}\right.$ vaso $^{-1}$ e $738,1 \mathrm{mg}$ vaso $^{-1}$ de N) obtidos no nível zero de compactação, sob os respectivos manejos.

Para o P (Figura 1b), a compactação também diminuiu os teores na parte aérea das plantas, atingindo no nível máximo de compactação, no M1, uma redução de 35,5\%; no M2, 27,0\% e no M3, 20,0\%, em relação as maiores médias $\left(71,8 \mathrm{mg}\right.$ vaso $^{-1} ; 46,8 \mathrm{mg}$ vaso $^{-1}$ e $41,4 \mathrm{mg}$ vaso $^{-1} \mathrm{de}$ $\mathrm{P})$, alcançados no solo não compactado. No caso do $\mathrm{K}$ (Figura 1c), essa redução, no nível máximo de compactação, chegou a $24,3 \%$ no M1; $23,7 \%$ no M2 e $20,1 \%$ no M3, em relação as maiores médias $\left(2.262 \mathrm{mg} \mathrm{vaso}^{-1}, 1.771,3 \mathrm{mg}\right.$ vaso $^{-1}$ e $1.723 \mathrm{mg} \mathrm{vaso}^{-1} \mathrm{de} \mathrm{K}$ ), acumuladas na parte aérea das plantas, cultivadas no solo sob o nível zero de compactação.

Estes resultados corroboram com os obtidos por Pedrotti et al. (1994), que constataram redução na absorção de N, P e K em plantas de arroz, milho e soja, à medida que se elevou a densidade do solo. Isso, deve-se à redução da porosidade total do solo, que conseqüentemente, diminuiu a taxa de infiltração, a condutividade hidráulica e o fluxo de água no solo, que são essenciais para a absorção de água e de nutrientes pelas raízes (RIBEIRO, 1999), principalmente no caso do $\mathrm{N}$, em que o contato íon-raiz ocorre predominantemente por fluxo de massa. Além disso, a compactação reduz a aeração do solo e a mineralização da matéria orgânica, aumenta a energia de retenção da água no solo, elevando sua viscosidade, e a interação dos íons de fosfato e de potássio com a superfície dos colóides ao longo de sua trajetória de difusão, fazendo com que os mesmos tenham que se movimentarem cada vez mais próximo de superfícies positivamente carregadas, principalmente, em solos argilosos com baixa umidade (NOVAIS \& SMYTH, 1999). (a)

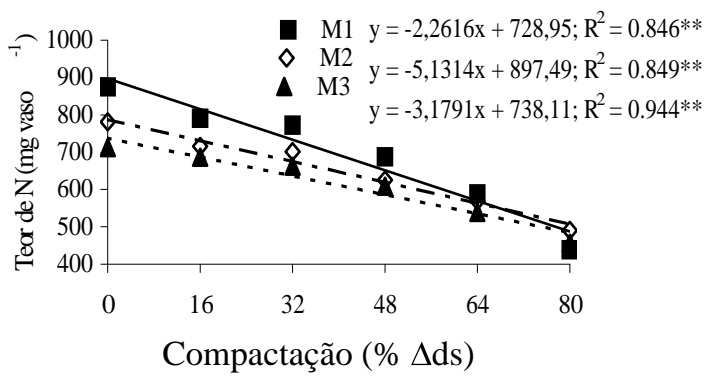

(b)

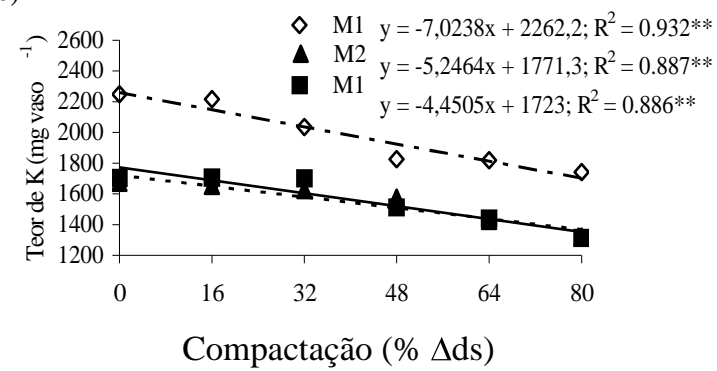

(c)

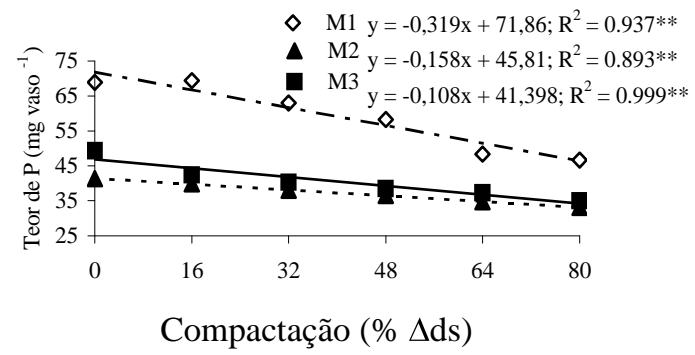

FIGURA 1 - Teores de nitrogênio (a), fósforo (b) e de Potássio (c) na matéria seca da parte aérea de plantas de arroz em função do desdobramento da interação compactação dentro de manejos de água. UFLA, LavrasMG, 2004.

Por outro lado, o manejo com maior disponibilidade de água favoreceu a absorção de $\mathrm{P}$ e de $\mathrm{K}$ na parte aérea das plantas em todos os níveis de compactação e, do N, nos níveis mais elevados de compactação. Assim, comparando os valores máximos e mínimos dos teores de P (Figura 1b): 71,8 e 46,3 $\mathrm{mg} \mathrm{vaso}^{-1}$ de P no M1; 46,8 e 34,2 mg vaso ${ }^{-1}$ de $\mathrm{P}$ no M2 e, 41,4 e 33,1 $\mathrm{mg} \mathrm{vaso}^{-1}$ de P no M3; e os de K (Figura 1c): 2.226 e $1.700 \mathrm{mg}$ vaso $^{-1}$ de $\mathrm{K}$ no M1; 1.771 e $1.351 \mathrm{mg} \mathrm{vaso}^{-1}$ de K no M2 e, 1.723 e $1.367 \mathrm{mg}$ vaso $^{-1}$ de K no M3 obtidos sob os níveis mínimos e máximos de compactação, respectivamente; verifica-se que, mesmo havendo redução nos teores de $\mathrm{P}$ e de $\mathrm{K}$, independentemente do manejo de água; os menores valores 
(46,3 mg vaso ${ }^{-1}$ de $\mathrm{P}$, e $1700 \mathrm{mg}$ vaso $^{-1}$ de K) obtidos no nível máximo de compactação sob o M1, foram praticamente iguais as maiores médias alcançadas no solo não compactado sob os manejos M2 e M3, respectivamente. Portanto, pode-se inferir que o acúmulo dos teores de $\mathrm{P}$ e de $\mathrm{K}$ na parte aérea das plantas foram mais influenciados pela disponibilidade de água no solo do que pelos níveis de compactação.

Esse resultado corrobora, em parte, os encontrados por Carvalho Júnior (1987), Crusciol (2001) e Scalco (1983), os quais obtiveram aumento da absorção de N, P e K na parte aérea de plantas de arroz, à medida que se elevaram os teores de água no solo. Isso é explicado pela elevação do pH no solo saturado, favorecendo a disponibilidade dos nutrientes, o incremento do fluxo difusivo do P e do K (COSTA, 1998; RIBEIRO, 1999), aumentos da eficiência fotossintética, das taxas de respiração e transpiração da planta, além da redução da resistência a penetração das raízes (HOFFMANN \& JUNGK, 1995; STONE et al., 2002), resultando na maior absorção desses e de outros nutrientes.

A massa seca de raízes obtida em função do desdobramento da interação compactação $\mathrm{x}$ manejos de água encontra-se na Figura 2. No geral, a maior disponibilidade de água no solo favoreceu as médias de massa seca das raízes por vaso, independentemente dos níveis de compactação. Isso pode ser explicado pela maior eficiência fotossintética da planta, a redução da resistência à penetração e ao aumento da absorção de nutrientes em ambientes com maior umidade, sobretudo do $\mathrm{N}$ e do $\mathrm{P}$ que são os elementos que mais contribuem para o desenvolvimento do sistema radicular.

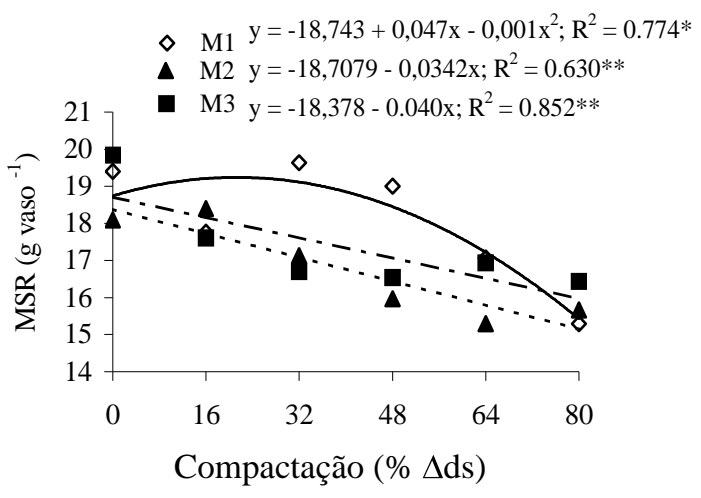

FIGURA 2 - Massa seca de raízes (MSR) obtida em função do desdobramento da interação compactação x manejos de água. UFLA, Lavras-MG, 2004.
Por outro lado, a compactação do solo afetou a massa seca das raízes de modo distinto dependendo do manejo de água. No manejo (M1), as médias se ajustaram a um modelo de regressão quadrática com coeficiente de determinação estimado em $77,4 \%$. Observou-se um moderado aumento na massa de raízes, atingindo a produção máxima de $19,8 \mathrm{~g}$ vaso $^{-1}$ no nível de compactação $23,5 \%$ da $\Delta$ ds equivalente à densidade de $1,17 \mathrm{~kg} \mathrm{dm}^{-3}$, mantendo-se praticamente estável até o nível de $48 \%$ da $\Delta$ ds (densidade $1,23 \mathrm{~kg} \mathrm{dm}^{-3}$ ). Isso ocorreu devido a maior disponibilidade de água e de nutrientes, ocasionada pela saturação do solo, atenuando os efeitos depressivos da compactação sobre o desenvolvimento do sistema radicular, até o nível de $48 \%$ da Dds. A partir desse ponto, houve uma acentuada redução com o aumento da compactação, tendo em vista as restrições na disponibilidade de nutrientes e o aumento da resistência à penetração das raízes ocorrido nos níveis mais elevados de compactação.

Nos manejos M2 e M3, a massa das raízes decresceu com o incremento da compactação, cujos valores se ajustaram a modelos de regressão linear decrescente. Para cada um por cento de variação da amplitude da densidade do solo, a redução média da MSR foi de $0,037 \mathrm{~g}$ de raiz vaso ${ }^{-1}$, devido a redução do número de raízes, observado com o aumento da compactação. Entretanto, não houve impedimento total do desenvolvimento das raízes, mesmo no nível máximo de compactação do solo sob os manejos de água avaliados.

Essa redução ocorreu devido às alterações nas propriedades físico-hídricas e químicas do solo já mencionadas. Além do mais, o comprimento das raízes é reduzido com o aumento da resistência à penetração, provocado pela compactação (HOFFMANN \& JUNGK, 1995).

Esses resultados corroboram os obtidos por Guimarães \& Moreira (2001), os quais observaram redução na densidade do sistema radicular do arroz de terras altas e de feijoeiro, a partir da densidade de $1,2 \mathrm{~kg} \mathrm{dm}^{-3}$. Por outro lado, divergem em parte, dos resultados obtidos por Groghmann \& Queiroz Neto (1966) que constataram impedimento físico ao desenvolvimento das raízes de plantas de arroz, quando a densidade do solo atingiu valores superiores a 1,38 $\mathrm{kg} \mathrm{dm}^{-3}$ num Podzólico Vermelho Amarelo e $1,42 \mathrm{~kg} \mathrm{dm}^{-3}$ no Latossolo Roxo.

O resultado do número de perfilhos por vaso obtido em função dos três manejos de água encontram-se na Tabela 2, e sob os seis níveis de compactação são mostrados na Figura 3.

Ciênc. agrotec., Lavras, v. 29, n. 5, p. 940-947, set./out., 2005 
TABELA 2 - Número de perfilhos vaso ${ }^{-1}$ obtido sob três manejos de água, considerando a média dos seis níveis de compactação.UFLA, Lavras, MG, 2004.

\begin{tabular}{lc}
\hline \multicolumn{1}{c}{ Manejo de água } & Panículas vaso $^{-1}$ \\
\hline M1 - Solo saturado & $25,7 \mathrm{a}$ \\
M2 - Irrigado quando eram consumidos de 25\% a 30\% da AD & $21,9 \mathrm{~b}$ \\
M3 - Irrigado quando eram consumidos de 50\% a 60\% da AD & $21,7 \mathrm{~b}$ \\
DMS a 5\% $=1,02$ & \\
\hline
\end{tabular}

O número de perfilhos foi afetado pelos diferentes teores de água no solo. O manejo M1 favoreceu a média do número de perfilhos.vaso ${ }^{-1}$, superando em $17,4 \%$ a média obtida sob o M2 que, por sua vez, não diferiu do M3. Esse aumento propiciado pelo M1, deve-se a maior disponibilidade e absorção de nutrientes pela plantas cultivadas no solo saturado, sobretudo do $\mathrm{N}$ e $\mathrm{P}$, nos níveis mais elevados de compactação, em que a absorção desses nutrientes foi bastante reduzido nos manejos com menor disponibilidade de água. $\mathrm{O}$ resultado foi semelhante aos obtidos por Rodrigues (1998), o que também observou aumento do número de perfilhos de plantas de arroz sob maiores teores de água no solo.

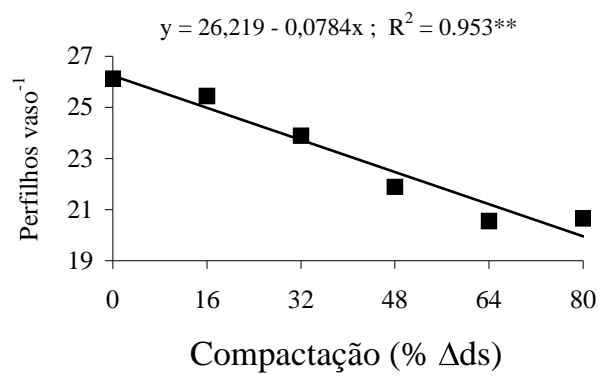

FIGURA 3 - Efeito dos níveis de compactação sobre o número de perfilhos vaso ${ }^{-1}$, considerado a média dos três manejos de água. UFLA, Lavras-MG, 2004.

Quanto aos níveis de compactação (Figura 3), houve decréscimo do número perfilhos vaso ${ }^{-1}$, de 26,2 observado no nível zero de compactação, para 19,9 no nível máximo, equivalendo a uma redução de 24,0\%. Ribeiro (1999) também observou redução linear no número de perfilhos de arroz com o aumento da compactação. Essa redução é explicada pela redução da disponibilidade e a absorção de nutrientes, sobretudo de $\mathrm{N}$ que é o elemento que mais contribui para o perfilhamento do arroz. A compactação limita a aeração e, por conseguinte, a mineralização da matéria orgânica, o fornecimento de $\mathrm{N}$ e de outros nutrientes e o desenvolvimento do sistema radicular.
A produção de massa seca da parte aérea de plantas obtidas em função do desdobramento da interação compactação x manejo de água encontra-se na Figura 4. Comparando as médias obtidas entre os diferentes manejos de água, verifica-se que a produção de massa seca da parte aérea das plantas (MSPA) foi favorecida pelos maiores teores de água de água no solo, independentemente dos níveis de compactação. Isso ocorreu devido à redução da resistência à penetração das raízes, a maior disponibilidade e absorção de N, P e K e de outros nutrientes, proporcionando maior eficiência fotossintética, que conseqüentemente, incrementou o desenvolvimento do sistema radicular, o número de perfilhos por vaso e a parte aérea das plantas cultivadas no solo com maiores teores de água. Esse resultado assemelha-se aos obtidos por Crusciol (2001) e Stone \& Silva (1998) que também observaram maior produção de MSPA em arroz de terras altas com a maior umidade do solo, os quais atribuíram seus resultados à maior absorção de água e de nutrientes pelas plantas.

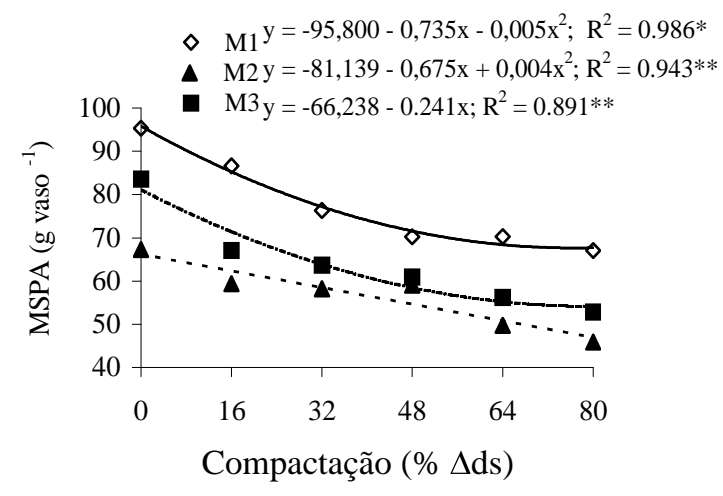

FIGURA 4 - Massa seca da parte aérea de plantas de arroz obtida em função dos níveis de compactação e manejo de água. UFLA, Lavras-MG, 2004. 
Por outro lado, a compactação do solo reduziu a produtividade de massa seca da parte aérea das plantas, independentemente do manejo de água, à medida que se aumentou o nível de compactação. Os maiores valores da MSPA foram obtidos no nível $0 \%$ da $\Delta$ ds, ou seja, 95,8; 81,1 e 66,2 g vaso $^{-1}$ nos manejos M1, M2 e M3, respectivamente, e os menores valores, no nível máximo de compactação ( $80 \%$ da $\Delta \mathrm{ds}$ ), que corresponde a 67,9 ; $54,1 \mathrm{e} 46,9 \mathrm{~g} \mathrm{vaso}^{-1}$, respectivamente. Isto corresponde a decréscimos de $29 \%, 33 \%$ e $29 \%$ da produção da MSPA, observados nos manejos M1, M2 e M3, respectivamente.

Essa redução na MSPA é atribuída às alterações nas propriedades físico-hídricas dos solos, já mencionadas, provocada pela compactação, reduzindo a absorção de nutrientes e o acúmulo de carbono pela fotossíntese que, conseqüentemente, reduziu o perfilhamento a elongação das células do sistema radicular e da parte aérea das plantas por vaso.

Esse resultado está de acordo com os obtidos por Ribeiro (1999), que encontrou redução linear e decrescente da MSPA de plantas de arroz à medida que se elevou o grau de compactação. Porém, divergem dos encontrados por Leite et al. (2003), que mostram aumento linear e crescente da MSPA de plantas de arroz com o incremento da compactação em um solo de textura média.

Entretanto, comparando as médias da produção de massa seca da parte aérea (Figura 4), obtidas sob os níveis mínimo e máximo de compactação nos diferentes manejos de água $\left(95,8\right.$ e $67,9 \mathrm{~g}$ vaso $^{-1}$ no M1; 81,1 e $54,1 \mathrm{~g}$ vaso ${ }^{-1}$ no $\mathrm{M} 2$ e 66,2 e $46,9 \mathrm{~g} \mathrm{vaso}^{-1}$ no M3, respectivamente), verificase que, mesmo havendo redução na produção da MSPA, independentemente do manejo de água, a menor produção (69,7 $\left.\mathrm{g} \mathrm{vaso}^{-1}\right)$, obtida no nível máximo de compactação sob o M1, foi 2,6\% superior à maior média $\left(66,2 \mathrm{~g} \mathrm{vaso}^{-1}\right)$, alcançada no solo não compactado sob o M3. Isso sugere que a produtividade média de massa seca da parte aérea das plantas de arroz foi mais influenciada pelos teores de água no solo do que pelos níveis de compactação. Portanto, infere-se que a compactação do solo per si não deve ser fator limitante para a adoção do sistema de cultivo de plantio direto do arroz, em várzeas úmidas, já que os solos dessas várzeas, geralmente permanecem a maior parte do ciclo da cultura, praticamente $100 \%$, saturados com a água.

\section{CONCLUSÕES}

Para as condições em que foi conduzido o experimento conclui-se que: a) A compactação do solo reduz a absorção de N, P, $\mathrm{K}$, a produção de massa seca de raízes, o número de perfilhos e a produção de massa seca da parte aérea das plantas de arroz.

b) A disponibilidade de água no solo tem maior influência sobre a absorção de N, P, K e na produção de massa seca da parte aérea das plantas de arroz do que a compactação do solo.

c) O manejo de água com o solo saturado favorece a absorção de $\mathrm{P}$ e $\mathrm{K}$ na parte aérea das plantas, o desenvolvimento do sistema radicular, o número de perfilhos e a produtividade de massa seca da parte aérea das plantas.

\section{REFERÊNCIAS BIBLIOGRÁFICAS}

CARVALHO JUNIOR, A. C. de. Efeito da adubação potássica em cultivares do arroz (Oryza sativa $\mathbf{L}$.) de sequeiro sob déficit hídrico, em solo sob cerrado. 1987. 160 f. Dissertação (Mestrado) - Escola Superior de Agricultura de Lavras, Lavras, 1987.

COSTA, J. P. V. da. Fluxo de difusivo de fósforo e de potássio em Latossolos. Viçosa: UFV, 1998. 67 p.

CRUSCIOL, C. A. C. Crescimento radicular, nutrição e produção de cultivares de arroz de terras altas em função da disponibilidade hídrica e de fósforo. $2001.111 \mathrm{f}$. Tese (Livre docência) - Universidade Estadual Paulista, Botucatu, 2001.

DIAS, A. D.; GOMES A. da S.; PENA, Y. A.; SOUSA, R. O. Desempenho de Arroz irrigado em plantio direto sob diferentes coberturas vegetais. In: REUNIÃO DA CULTURA DO ARROZ IRRIGADO, 21., 1995, Porto Alegre. Anais... Porto Alegre: IRGA, 1995. p. 146-148.

EMPRESA BRASILEIRA DE PESQUISA AGROPECUÁRIA. Centro Nacional de Pesquisa de Solos. Manual de métodos de análise de solos. 2. ed. Rio de Janeiro, 1997. 212 p. (Documentos, 1).

GOMES, A. da S.; VAHL, L. C.; PAULETTO, A. E.; PORTO, V. H. da F.; GONZALES, B. D. Fundamentos para a cultura do arroz irrigado. In: EMPRESA BRASILEIRA DE PESQUISA AGROPECUÁRIA. Centro de Pesquisa Agropecuária de Terras Baixas de Clima Temperado. Fundamentos para a cultura do arroz irrigado. Campinas: Fundação Cargill, 1985. p. 251-274.

Ciênc. agrotec., Lavras, v. 29, n. 5, p. 940-947, set./out., 2005 
GROHMANN, F.; QUEIROZ NETO, J. P. Efeito da compactação artificial de dois solos limo-argilosos sobre a penetração das raízes de algodão. Bragantia, Campinas, v. 25, n. 38, p. 421-432, dez. 1966.

GUIMARÃES, C. M.; MOREIRA, J. A. A. Compactação do solo na cultura do arroz de terras altas. Pesquisa Agropecuária Brasileira, Brasília, v. 36, n. 4, p. 703-707, abr. 2001.

HOFFMANN, C.; JUNGK, A. Growth and phosphorus supply of sugar beet as affected by soil compaction and water tension. Plant and Soil, Dodrecht, v. 176, n. 1, p. 15-25, Sept. 1995.

KLUTHCOUSKI, J. Efeito de manejo em alguns atributos de um latossolo roxo sob cerrado e nas características produtivas de milho, soja, arroz e feijão, após oito anos de plantio direto. 1998. $179 \mathrm{f}$. Tese (Doutorado em Fitotecnia) - Escola Superior de Agricultura Luiz de Queiroz, Piracicaba, 1998.

LEITE, G. M. V.; RIBEIRO, G. J. T.; GROSS, M. R.; SCHMIDT, P. A.; CORRÊA, J. B. D.; SILVEIRA, T. Influência da compactação na germinação e desenvolvimento do arroz em três classes de solo. In: CONGRESSO BRASILEIRO DE CIÊNCIA DO SOLO, 29., 2003, Ribeirão Preto-SP. Anais... Ribeirão Preto: UNESP, 2003. CD-ROM.

LIER, J. van. Índices da disponibilidade de água para as plantas. In: NOVAIS, R. F.; ALVAREZ V.; SCHAEFER, C. E. G. R. (Eds.). Tópicos em ciência do solo. Viçosa: SBCS, 2000. v. 1, p. 95-106.

NOVAIS, R. F.; SMYTH, T. J. Fósforo em solo e planta em condições tropicais. Viçosa: UFV, 1999. 399 p.

PASSIOURA, J. B. Soil structure and plant growth. Australian Journal of soil Research, Collingwood, v. 29, p. 717-729, 1991.

PEDROTTI, A.; VAHL, L. C.; PAULETTO, E. A. Absorção de nutrientes em diferentes níveis de compactação de um Planossolo. In: REUNIÃO BRASILEIRA DE FERTILIDADE DO SOLO E NUTRIÇÃO DE PLANTAS, 21., 1994, Petrolina. Anais... Petrolina: EMBRAPA/CPATSA, 1994. p. 302-304.

RIBEIRO, M. A. V. Resposta da soja e do eucalipto a fósforo em solos de diferentes texturas, níveis de densidade e de umidade. 1999. 71 p. Tese (Doutorado) - Universidade Federal de Lavras, Lavras, 1999.
RODRIGUES, R. A. F. Efeitos do manejo de água nas características fenológicas e produtivas do arroz (Oryza sativa $\mathrm{L}$ ) cultivado em condições de sequeiro sob irrigação por aspersão. 1998. 75 f. Tese (Doutorado) - Universidade Estadual Paulista, Botucatu, 1998.

ROSOLEM, C. A.; VALE, L. S. R.; GRASSE, H. F.; MORAES, H. F. Sistema radicular e nutrição do milho em função da calagem e da compactação do solo. Revista Brasileira de Ciência do Solo, Viçosa, v. 18, p. 491-497, 1994.

SCALCO, M. S. Efeito do manejo da água no crescimento e absorção de N, P, K, Fe, Mn, e Zn pelo arroz (Oryza sativa L. CV. "IAC 25”). 1983. 90 f. Dissertação (Mestrado) - Escola Superior de Agricultura de Lavras, Lavras, 1983.

SÉGUY, L.; BOUZINAC, S.; MARONEZZI, A. C.; TAFFAREL, V.; TAFFAREL, J. Plantio direto do arroz de sequeiro de alta tecnologia na zona tropical úmida do centro-norte do Mato Grosso. Informações Agronômicas, Piracicaba, n. 86, p. 1-28, jun. 1999. Encarte técnico.

SILVEIRA, P. M. da. Densidade do solo e micronutrientes em arroz de terras altas. In: CONGRESSO DA CADEIA PRODUTIVA DO ARROZ, 1.; REUNIÃO NACIONAL DE PESQUISADEARROZ-RENAPA, 7.,2002,Florianópolis.Anais... Florianópolis:EMBRAPA Arroz e Feijão, 2002. p. 538-539.

STONE, L. F.; SILVA, J. G. da. Resposta do arroz de sequeiro à profundidade de aração: adubação nitrogenada e condições hídricas do solo. Pesquisa Agropecuária Brasileira, Brasília, v. 33, n. 6, p. 891-897, jun. 1998.

STONE, L. F.; GUIMARÃES, C. M.; MOREIRA, J. A. A. Compactação do solo na cultura do feijoeiro: I. nas propriedades físico-hídricas do solo. Revista Brasileira de Engenharia Agrícola e Ambiental, Campina Grande, v. 6, n. 2, p. 213-218, maio/ago. 2002.

TEDESCO, M. J.; GIANELHO, C.; BISSANI, C. A.; BOHNEN, U.; VOLKWEISS, S. J. Análises de solo, de plantas e outros materiais. 2. ed. rev. e ampl. Porto Alegre: UFRGS, 1995. 174 p. (Boletim técnico, 5).

WEBER, L.; MAECHEZAN, E.; CARLESSO, R.; SEGABINAZZI, T. Desempenho de cultivares de arroz irrigado em diferentes sistemas de cultivo. In: CONGRESSO BRASILEIRO DE ARROZ IRRIGADO, 1.; REUNIÃO DA CULTURA DO ARROZ IRRIGADO, 23., 1999, Pelotas. Anais... Pelotas: EMBRAPA Clima Temperado, 1999. p. 296-298. 